\title{
Prevalence of headache in Europe: a review for the Eurolight project
}

\author{
Lars Jacob Stovner • Colette Andree
}

Received: 19 January 2010/Accepted: 15 April 2010/Published online: 16 May 2010

(c) The Author(s) 2010. This article is published with open access at Springerlink.com

\begin{abstract}
The main aim of the present study was to do an update on studies on headache epidemiology as a preparation for the multinational European study on the prevalence and burden of headache and investigate the impact of different methodological issues on the results. The study was based on a previous study, and a systematic literature search was performed to identify the newest studies. More than $50 \%$ of adults indicate that they suffer from headache in general during the last year or less, but when asked specifically about tension-type headache, the prevalence was $60 \%$. Migraine occurs in 15\%, chronic headache in about $4 \%$ and possible medication overuse headache in $1-2 \%$. Cluster headache has a lifetime prevalence of $0.2-0.3 \%$. Most headaches are more prevalent in women, and somewhat less prevalent in children and youth. Some studies indicate that the headache prevalence is increasing during the last decades in Europe. As to methodological issues, lifetime prevalences are in general higher than 1-year prevalences, but the exact time frame of headache (1 year, 6 or 3 months,
\end{abstract}

On behalf of the Eurolight Steering Committee.

\section{J. Stovner $(\square)$}

Department of Neuroscience, Norwegian National Headache Centre, Norwegian University of Science and Technology, 7006 Trondheim, Norway

e-mail: lars.stovner@ntnu.no

\section{J. Stovner}

St. Olavs Hospital, 7006 Trondheim, Norway

C. Andree

CRP Santé, Luxembourg City, Luxembourg

C. Andree

Department of Pharmaceutical Sciences,

University of Basel, Basel, Switzerland or no time frame stated) seems to be of less importance. Studies using personal interviews seem to give somewhat higher prevalences than those using questionnaires.

Keywords Epidemiology · Prevalence · Headache · Migraine $\cdot$ Medication overuse

\section{Introduction}

The Eurolight project (http://www.eurolight-online.eu) is an initiative supported by the EC Public Health Executive Agency launched in May 2007. Its objectives are to bring together the relevant medical, scientific and lay organizations, and to gather updated reliable comparable information regarding migraine, tension-type and chronic headache. It will be the first data collection on headaches at EU level focusing on a holistic, patient-driven and scientifically validated approach, aiming to fill in the main holes in our knowledge by performing comparable studies on headache prevalence and impact in selected European countries (Austria, France, Germany, Italy, Lithuania, the Netherlands, Spain, UK, Ireland and Luxembourg). A pilot study has already been performed in Luxembourg. The present review of the prevalence of various headaches in Europe was performed as a part of the Eurolight project to assess the current state of knowledge before the data from the current project are published.

A previous study on the headache prevalence in Europe covered the data up till 2005 [1]. The present review will include all previous studies, including relatively recently published reviews [1-3] with the addition of new relevant studies that have appeared in the years between 2005 and 2009. The way the research methodology can influence the results has been thoroughly discussed in some of these and 
other publications $[1,4,5]$. The aim of the present article was to give an update on the prevalence of the most important headache types in Europe, to identify gaps in our present knowledge and to analyse some methodological issues in order to choose an optimal methodology for the studies to be performed for the EUROLIGHT project.

\section{Methodology}

Literature search

A comprehensive literature search was performed to identify population-based studies of headache and migraine. Searches were performed with PubMed using the expressions "migraine epidemiology", "headache epidemiology" and "migraine prevalence" or "headache prevalence" for each European country. References in relevant publications have also been examined. Only studies in English, German, French or Spanish were considered.

\section{Data extraction}

The information extracted was the country of origin, year of publication, population characteristics and the prevalence estimates for headache, migraine, tension-type headache (TTH) and chronic headache, both overall and for each gender, and for various age categories.

\section{Case definitions}

Only studies where the headache diagnoses are made according to the International Classification of Headache Disorders, first edition (ICHD-1) from 1988 [6] or according to ICHD-2 from 2004 [7] have been used. This classification has later been incorporated in the International Classification of Diseases (ICD-10) [8]. Hence, we have included epidemiologic studies that have appeared after 1988 on migraine (ICD-10 diagnosis G43) and TTH (G44.2), the two types that affect the great majority of headache patients. For migraine, we have not distinguished between migraine with (G43.1) and without (G43.0) aura. This differentiation can reliably be made only in studies using personal interview, preferably by a headache specialist. In addition, it is not known whether the two types differ markedly with regard to the patients' suffering and subsequent economic consequences. For practical reasons, the diagnosis in most headache epidemiologic studies has been made according to somewhat modified criteria, and such studies have also been included.

In order to comprise all headache patients, we have also included epidemiologic studies that have investigated headache in general. The term "headache" is not, however, defined in the ICHD classifications, and we have therefore included studies on headache prevalence that appeared before 1988. For TTH, the term "chronic" has been applied to patients who have this type of headache for $\geq 15$ days per month on average for $\geq 3$ months (ICHD- 1 and -2). In many headache studies, a similar definition has been given to patients with headache, irrespective of whether it is of the tension type or not. We have also gathered data on "chronic headache" (i.e. $\geq 15$ days per month or "daily" headache) to assess the prevalence of these patients who are probably most incapacitated by their condition. A subgroup of these patients are overusing acute medication, a condition termed "Medication overuse headache" (MOH) in the IDHD-2. We have also collected data on this frequent and possibly preventable condition.

\section{Source populations}

For our purpose, we have included only studies performed on the whole population or a representative sample of the whole population within a certain age range in a community, town or country. We have accordingly not included studies based on selected populations (clinic based, in workplaces, among university students, etc.). Since the primary school is obligatory in all European countries, studies on headache in children and youth based on schools have been included.

\section{Period prevalences}

For many patients, headache is troublesome only in certain phases of life. For this reason, most headache epidemiological studies have asked the subjects on headache within a limited time span, usually the last year. The 1-year prevalence figure indicates the proportion of the population that has an active disease, which is more relevant than lifetime prevalence for health economic calculations. Data on lifetime prevalence are also considered less reliable due to recall problems, at least in the elderly. In children and adolescents, one may assume that the lifetime and 1-year prevalences are not very different. The studies with 3-month or not specified timeframe has also been included since these time frames will also give a fairly accurate estimate of the proportion of the population with headache in the relatively recent past, usually not very different from the 1-year prevalence.

\section{Results}

Headache

Headache in general has been reported in 49 studies (Table 1), whereof 34 have concerned headache during 
Table 1 Studies on headache prevalence

\begin{tabular}{|c|c|c|c|c|c|c|c|c|c|c|c|}
\hline \multirow[t]{2}{*}{ Country (year) } & \multirow[t]{2}{*}{ Reference } & \multirow[t]{2}{*}{ Time frame } & \multirow[t]{2}{*}{ Method } & \multirow[t]{2}{*}{$N$} & \multirow[t]{2}{*}{ Age range (years) } & \multicolumn{3}{|c|}{ Headache } & \multicolumn{3}{|c|}{ Chronic headache } \\
\hline & & & & & & M & $\mathrm{F}$ & Total & M & $\mathrm{F}$ & Total \\
\hline \multicolumn{12}{|l|}{ Adults or all ages } \\
\hline Austria (2003) & Lampl [37] & $1-\mathrm{y}$ & P.i. & 997 & $\geq 15$ & 43.6 & 54.6 & 49.4 & & & \\
\hline Croatia $(2001,2003)$ & Zivadinov $[38,49]$ & L.t. & P.i. & 3,794 & $15-65$ & & & 65.2 & & & \\
\hline Denmark (1991) & Rasmussen [10] & $1-\mathrm{y}$ & P.i. & 740 & $25-64$ & & & & & & 3 \\
\hline Denmark (1991) & Rasmussen [10] & L.t. & P.i. & 740 & $25-64$ & 93 & 99 & 96 & & & \\
\hline Finland (1981) & Nikiforow [45] & $1-\mathrm{y}$ & P.i. & 200 & $>15$ & 69 & 83 & 77 & & & \\
\hline Finland (1981) & Nikiforow [45] & L.t. & P.i. & 200 & $>15$ & & & 91 & & & \\
\hline France (1992) & Henry [51] & L.t. & Q & 4,204 & $5-65$ & & & 35 & & & \\
\hline France (2002) & Henry [20] & N.s. & Q & 10,585 & $\geq 15$ & & & 29.2 & & & 3.0 \\
\hline France (2003) & Lanteri-Minet [17] & L.t. & Q & 10,585 & $\geq 15$ & & & & 1.6 & 4.2 & 3 \\
\hline France (1996) & Michel [46] & $3-\mathrm{m}$ & Q & 9,411 & $>18$ & 39.0 & 58.0 & 49 & & & \\
\hline Germany (1994) & Gobel [52] & L.t. & Q & 4,061 & $\geq 18$ & & & 71.4 & & & \\
\hline Germany (2009) & Pfaffenrath [61] & $6-\mathrm{m}$ & P.i. & 7,417 & $\geq 20$ & & & 49.5 & & & \\
\hline Germany (2009) & Radke [62] & $1-y$ & T.i. & 7,341 & $\geq 18$ & 53.0 & 66.6 & 60.2 & & & \\
\hline Georgia (2009) & Katsarava [12] & $1-\mathrm{y}$ & P.i. & 1,145 & $\geq 16$ & & & 46.3 & & & 7.6 \\
\hline Greece (1996) & Mitsikostas [18] & $1-y$ & Q & 3,501 & $15-75$ & 19.0 & 40.0 & 29 & 2.1 & 6.8 & 4.5 \\
\hline Italy (1988) & D’Alessandro [47] & $1-y$ & Q & 1,154 & $>7$ & 35.3 & 46.2 & 46 & & & \\
\hline Netherlands (2006) & Wiendels [13] & $3-\mathrm{m}$ & Q & 16,232 & $25-55$ & & & & & & 3.7 \\
\hline Norway (2000) & Hagen [15] & $1-y$ & Q & 51,383 & $\geq 20$ & 29.6 & 45.7 & 37.7 & 1.7 & 2.8 & 2.4 \\
\hline Norway (2008) & Grande [22] & $1-\mathrm{y}$ & Q & 20,598 & $30-44$ & & & & & & 2.9 \\
\hline Norway (2008) & Russell [43] & $1-y$ & Q & 21,800 & $20-80$ & 69.6 & 84.0 & 77.2 & & & \\
\hline Portugal (1995) & Pereira Monteiro [53] & L.t. & Q & 2,008 & All ages & & & 88.6 & & & 4.1 \\
\hline Spain (1999) & Castillo [14] & $1-y$ & Q & 2,253 & $>14$ & & & & 1.0 & 8.7 & 4.7 \\
\hline Spain (1994) & Laínez [50] & L.t. & P.i. & 2,231 & $16-65$ & & & 86.7 & & & \\
\hline Sweden (2001) & Dahlof [42] & $1-\mathrm{y}$ & Q & 1,668 & $18-74$ & 50 & 76 & 63 & & & \\
\hline Sweden (2006) & Molarius [63] & $3-\mathrm{m}$ & Q & 43,770 & $18-79$ & 10.4 & 22.9 & 16.7 & & & \\
\hline Turkey (2005) & Boru [64] & L.t & P.i. & 1,835 & $15-45$ & & 70.9 & & & & \\
\hline UK (1975) & Waters [65] & $1-\mathrm{y}$ & Q & 1,718 & $>21$ & 63.5 & 78.4 & 71.0 & & & \\
\hline UK (2005) & Boardman [48] & $1-\mathrm{y}$ & Q & 1,589 & $18-90$ & & & 76 & & & \\
\hline UK (1977) & Crisp [66] & L.t. & Q & 727 & $>7$ & 35.3 & 46.2 & & & & \\
\hline UK (2003) & Boardman [67] & L.t. & Q & 1,662 & $\geq 18$ & 90.2 & 94.4 & 92.6 & & & \\
\hline UK (2003) & Boardman [67] & $3-\mathrm{m}$ & Q & 1,662 & $\geq 18$ & 62.0 & 76.8 & 70.3 & & & \\
\hline \multicolumn{12}{|l|}{ Children and youth } \\
\hline Finland (1983) & Sillanpää [68] & $1-y$ & Q & 3,784 & 13 & 79.8 & 84.2 & 82.0 & & & \\
\hline Finland (1994) & Metsähonkala [69] & $1-\mathrm{y}$ & Q & 3,580 & $8-9$ & & & 36.5 & & & \\
\hline Finland (1991) & Sillanpaa [70] & $1-\mathrm{y}$ & Q & 4,405 & 5 & & & 19.5 & & & \\
\hline Finland (1994) & Metsähonkala [69] & L.t. & Q & 3,580 & $8-9$ & & & 36.5 & & & \\
\hline Germany (2004) & Roth-Isigkeit [71] & $3-\mathrm{m}$ & Q & 735 & $10-18$ & 58.9 & 73.1 & 66 & & & \\
\hline Italy (1995) & Raieli [72] & $1-y$ & P.i. & 1,445 & $11-14$ & 19.9 & 28.1 & 23.9 & & & \\
\hline Norway (2004) & Zwart [19] & $1-y$ & Q & 8,255 & $13-19$ & 69.4 & 84.2 & 76.8 & 0.2 & 0.8 & 0.5 \\
\hline Serbia (2007) & Milanovic [73] & L.t. & P.i. & 1,259 & $7-12$ & & & 32.8 & & & \\
\hline Sweden (2004) & Laurell [33] & $1-y$ & Q & 1,850 & $7-15$ & 39.3 & 50.3 & 44.8 & & & \\
\hline Sweden (1962) & Bille [74] & L.t. & Q & 8,993 & $7-15$ & 58 & 59.3 & 58.7 & & & \\
\hline Turkey (2005) & Bugdayci [75] & N.s. & P.i. & 5,777 & $8-16$ & 46.2 & 52.8 & 49.2 & & & 1.5 \\
\hline Turkey (2007) & Akyol & L.t. & Q & 7,721 & $9-17$ & 79.6 & 87.1 & 83.4 & & & \\
\hline Turkey (2006) & Karli [76] & $1-y$ & Q & 2,387 & $12-17$ & 45.1 & 59.8 & 52.2 & & & \\
\hline Turkey (2006) & Unalp [77] & N.s. & Q & 2,384 & $14-18$ & 36 & 53 & 46 & & & \\
\hline
\end{tabular}


Table 1 continued

\begin{tabular}{|c|c|c|c|c|c|c|c|c|c|c|c|}
\hline \multirow[t]{2}{*}{ Country (year) } & \multirow[t]{2}{*}{ Reference } & \multirow[t]{2}{*}{ Time frame } & \multirow[t]{2}{*}{ Method } & \multirow[t]{2}{*}{$N$} & \multirow[t]{2}{*}{ Age range (years) } & \multicolumn{3}{|c|}{ Headache } & \multicolumn{3}{|c|}{ Chronic headache } \\
\hline & & & & & & M & $\mathrm{F}$ & Total & $\mathrm{M}$ & $\mathrm{F}$ & Total \\
\hline UK (1977) & Deubner [78] & $1-y$ & $\mathrm{Q}$ & 600 & $10-20$ & 74.4 & 81.5 & 78.0 & & & \\
\hline UK (1994) & Abu-Arefeh [79] & $1-\mathrm{y}$ & Q & 2,165 & $5-15$ & & & 66 & & & \\
\hline \multicolumn{12}{|l|}{ Elderly } \\
\hline Italy (2001) & Prencipe [16] & $1-y$ & P.i. & 833 & $\geq 65$ & 36.6 & 62.1 & 51 & 2.5 & 6 & 4.4 \\
\hline Italy (2003) & Camarda [80] & $1-\mathrm{y}$ & P.i. & 1,031 & $\geq 65$ & 16.5 & 26.3 & 21.8 & & & \\
\hline
\end{tabular}

1-y 1-year prevalence, 3-m 3-month prevalence, 6-m 6-month prevalence, L.t. lifetime prevalence, N.s. prevalence not stated, P.i. personal interview, T.i. telephone interview, $Q$ questionnaire, $M$ males, $F$ females

the last year or less (here summarized as "current headache", also including studies where timeframe were not stated). Calculating the mean of all the studies comprising more than 205,000 adult participants, current headache occurred in $53 \%$ of adults $(61 \%$ among women and $45 \%$ among men). The prevalence in the 12 studies restricted to children and youth, including $>37,000$ participants, was the same $(53 \%)$, but the only two studies on the elderly, from Italy, showed a somewhat lower figure $(36 \%)$. The total lifetime prevalence of headache among adults was as expected higher than that of current headache $(77 \%)$.

\section{Migraine}

The studies on migraine are presented in Table 2. The mean prevalence of current migraine among $>170,000$ adults was $14.7 \%$ ( $8 \%$ in men and $17.6 \%$ in women). In studies restricted to children and youth $(>36,000$ participants), the prevalences were lower (9.2\% for all, $5.2 \%$ in boys and $9.1 \%$ in girls). Lifetime prevalences were higher (16, 11 and $20 \%$, respectively).

Most studies only report the prevalence of "strict migraine", i.e. cases that comply with all the criteria of either migraine without (ICHD-2 1.1) or with aura (ICHD-2 1.2). However, if also probable migraine (ICHD-2 1.6), i.e. cases which fulfil all but one of the criteria, is included, the proportion with migraine is almost doubled [9].

\section{TTH}

Nineteen studies have reported the TTH prevalences (Table 3). Overall, the prevalence of current TTH among $>66,000$ adults was $62.6 \%$, and chronic TTH (i.e. on $\geq 15$ days per month) occurred in $3.3 \%$. Much lower figures (current TTH $15.9 \%$, chronic TTH $0.9 \%$ ) were found in the nine studies among almost 25,000 children and youth.
Chronic headache and $\mathrm{MOH}$

The definitions of chronic headache varied considerably among studies. Only two studies used the same criteria for chronicity as with chronic TTH ( $>180$ days/year [10] or $>14$ days/month for more than 3 months during the last year [11]). Most other studies used a definition of $\geq 15$ days per month [12-16] or simply daily headache [17-19].

The 1-year prevalence of current chronic daily headache was $4.0 \%$ (mean of 8 studies) [10, 12, 14, 15, 18, 20-22]. A similar figure $(4.4 \%)$ was found in one study restricted to the elderly [16], but in studies on children and youth, the figure was lower (0.5\% among 13-19-year-old in Norway), and $1.5 \%$ among 8-16-year-old in Turkey. The highest figure $(7.6 \%)$ was found among adults in Georgia [12]. Medication overuse is frequent among those with chronic headache, and possible medication overuse headache (i.e. headache $\geq 15$ days per month and use of medication $\geq 3$ months) was found to affect $0.9 \%$ in Georgia [12] and $1 \%$ of adults in Spain $[14,23]$. In the HUNT studies in Norway from the 1990 s the prevalence was $1 \%$ in adults [24] and $0.5 \%$ in adolescents [25], whereas a more recent study showed $1.7 \%$ [26]. In Germany, a recent study demonstrated a prevalence of $2 \%$ [27].

\section{Cluster headache}

In comparison to migraine and $\mathrm{TTH}$, cluster headache is rare, and to make the diagnosis from questionnaires alone has never been validated. Therefore, the prevalence should preferably be made by personal interview and examination by a neurologist in a large population. A lifetime prevalence of $0.326 \%$ was found in a study in which the diagnosis was made by face-to-face interview by a headache expert among more than 1,800 inhabitants of a Norwegian rural community [28]. This is similar to the figure $(0.279 \%)$ found in an Italian town among $>10,000$ patients registered in the lists of general practitioners, the sample being representative of the general population [29]. 
Table 2 Studies on migraine prevalence

\begin{tabular}{|c|c|c|c|c|c|c|c|c|}
\hline \multirow[t]{2}{*}{ Country (year) } & \multirow[t]{2}{*}{ Reference } & \multirow[t]{2}{*}{ Time frame } & \multirow[t]{2}{*}{ Method } & \multirow[t]{2}{*}{$N$} & \multirow[t]{2}{*}{ Age range (years) } & \multicolumn{3}{|c|}{ Migraine } \\
\hline & & & & & & M & $\mathrm{F}$ & Total \\
\hline \multicolumn{9}{|l|}{ Adults or all ages } \\
\hline Austria (2003) & Lampl [37] & $1-y$ & P.i. & 997 & $\geq 15$ & 6.1 & 13.8 & 10.2 \\
\hline Croatia (2001) & Zivadinov [38] & $1-y$ & P.i. & 3,794 & $15-65$ & 13 & 20.2 & 16.7 \\
\hline Croatia $(2001,2003)$ & Zivadinov $[38,49]$ & L.t. & P.i. & 3,794 & $15-65$ & 14.8 & 22.9 & 19 \\
\hline Denmark (1991) & Rasmussen [10] & $1-y$ & P.i. & 740 & $25-64$ & 6 & 15 & 10 \\
\hline Denmark (1991) & Rasmussen [10] & L.t. & P.i. & 740 & $25-64$ & 8 & 25 & 16.1 \\
\hline Denmark (1995) & Russell [81] & L.t. & Q & 4,061 & 40 & 12 & 24 & 18 \\
\hline Denmark (2005) & Lyngberg [36] & $1-y$ & P.i. & 207 & $25-36$ & 5.4 & 23.5 & 15.5 \\
\hline Denmark (2006) & Russell [44] & $1-\mathrm{y}$ & Q & 28,195 & $12-41$ & 13.9 & 24.3 & 19.1 \\
\hline France (1992) & Henry [51] & L.t. & Q & 4,204 & $5-65$ & 6.1 & 17.6 & 12.1 \\
\hline France (2002) & Henry [20] & N.s. & Q & 10,585 & $\geq 15$ & 10 & 23 & 17 \\
\hline France (2005) & Lantéri-Minet [9] & N.s. & Q & 10,532 & $\geq 18$ & 6.3 & 15.7 & 11.2 \\
\hline France (1996) & Michel [46] & $3-\mathrm{m}$ & Q & 9,411 & $>18$ & 8 & 18 & 15 \\
\hline Germany (1994) & Gobel [52] & L.t. & Q & 4,061 & $\geq 18$ & 22 & 32 & 27.5 \\
\hline Germany (2009) & Pfaffenrath [61] & $6-\mathrm{m}$ & P.i. & 7,417 & $\geq 20$ & & & 11.4 \\
\hline Germany (2009) & Radke [62] & $1-\mathrm{y}$ & T.i. & 7,341 & $\geq 18$ & 5.3 & 15.6 & 10.6 \\
\hline Georgia (2009) & Katsarava [12] & $1-\mathrm{y}$ & P.i. & 1,145 & $\geq 16$ & & & 15.6 \\
\hline Hungary (2000) & Bank [40] & $1-\mathrm{y}$ & Q & 813 & $15-80$ & 2.7 & 6.9 & 9.6 \\
\hline Netherlands (1999) & Launer [41] & $1-\mathrm{y}$ & Q & 6,491 & $20-65$ & 7.5 & 25 & 16.3 \\
\hline Netherlands (1999) & Launer [41] & L.t. & Q & 6,491 & $20-65$ & 13.3 & 33 & 23.2 \\
\hline Norway (2000) & Hagen [15] & $1-\mathrm{y}$ & Q & 51,383 & $\geq 20$ & 7.5 & 15.6 & 11.6 \\
\hline Norway (2006) & Sjaastad [82] & N.s. & P.i. & 1,838 & $18-65$ & 17.5 & 28.4 & 23.0 \\
\hline Norway (2008) & Russell [43] & L.t. & Q & 21,800 & $20-80$ & 18.1 & 34.1 & \\
\hline Portugal (1995) & Pereira Monteiro [53] & L.t. & Q & 2,008 & All & & & 8.8 \\
\hline Spain (1994) & Laínez [50] & L.t. & P.i. & 2,231 & $16-65$ & 8 & 17 & 12 \\
\hline Sweden (2000) & Mattsson [83] & L.t. & Q & 722 & $40-74$ & & 31 & \\
\hline Sweden (2000) & Mattsson [83] & $1-\mathrm{y}$ & Q & 728 & $40-74$ & & 18 & \\
\hline Sweden (2001) & Dahlöf [42] & $1-\mathrm{y}$ & Q & 1,668 & $18-74$ & 9.5 & 16.7 & 13.2 \\
\hline Sweden (2006) & Molarius [63] & $3-\mathrm{m}$ & Q & 43,770 & $18-79$ & 2.4 & 5.5 & 4.0 \\
\hline Switzerland (1994) & Merikangas [39] & $1-\mathrm{y}$ & P.i. & 379 & $29-30$ & & & 24.6 \\
\hline Turkey (2005) & Boru [64] & L.t. & P.i. & 1,835 & $15-45$ & & 15.8 & \\
\hline Turkey (2005) & Celik [55] & L.t. & P.i. & 386 & $>14$ & 9.3 & 29.3 & 19.9 \\
\hline Turkey (2002) & Kececi [56] & L.t. & P.i. & 947 & $\geq 7$ & 7.9 & 17.1 & 12.5 \\
\hline UK (2003) & Steiner [57] & $1-\mathrm{y}$ & T.i. & 4,007 & $16-65$ & 7.6 & 18.3 & 14.3 \\
\hline \multicolumn{9}{|l|}{ Children and youth } \\
\hline Finland (1994) & Metsähonkala [69] & L.t. & Q & 3,580 & $8-9$ & 3 & 2.3 & 2.7 \\
\hline Germany (2007) & Fendrich [84] & $3-\mathrm{m}$ & Q & 3,324 & $12-15$ & 4.4 & 9.3 & 6.9 \\
\hline Germany (2009) & Heinrich [85] & $6-\mathrm{m}$ & Q & 2,553 & $9-14$ & & & 13.1 \\
\hline Greece (1999) & Mavromichalis [86] & $1-\mathrm{y}$ & Q & 3,509 & $4-15$ & 5.2 & 7.3 & 6.2 \\
\hline Italy (1995) & Raieli [72] & $1-\mathrm{y}$ & P.i. & 1,445 & $11-14$ & 2.7 & 3.3 & 3.0 \\
\hline Norway (2004) & Zwart [19] & $1-\mathrm{y}$ & Q & 8,255 & $13-19$ & 4.8 & 9.1 & 7.0 \\
\hline Serbia (2007) & Milanovic [73] & L.t. & P.i. & 1,259 & $7-12$ & 2.1 & 4.6 & 3.3 \\
\hline Sweden (2004) & Laurell [33] & $1-y$ & Q & 1,850 & $7-15$ & 9.8 & 12.2 & 11.0 \\
\hline Turkey (2005) & Bugdayci [75] & N.s. & P.i. & 5,777 & $8-16$ & & & 10.4 \\
\hline Turkey (2004) & Zencir [87] & N.s. & Q & 2,490 & $11-18$ & 6.7 & 11.0 & 8.8 \\
\hline Turkey (2006) & Karli [76] & $1-y$ & Q & 2,387 & $12-17$ & & & 14.5 \\
\hline Turkey (2007) & Akyol [88] & L.t. & Q & 7,721 & $9-17$ & 7.8 & 11.7 & 9.7 \\
\hline
\end{tabular}


Table 2 continued

\begin{tabular}{|c|c|c|c|c|c|c|c|c|}
\hline \multirow[t]{2}{*}{ Country (year) } & \multirow[t]{2}{*}{ Reference } & \multirow[t]{2}{*}{ Time frame } & \multirow[t]{2}{*}{ Method } & \multirow[t]{2}{*}{$N$} & \multirow[t]{2}{*}{ Age range (years) } & \multicolumn{3}{|c|}{ Migraine } \\
\hline & & & & & & M & $\mathrm{F}$ & Total \\
\hline Turkey (2006) & Unalp [77] & $1-\mathrm{y}$ & Q & 2,384 & $14-18$ & & & 9.6 \\
\hline UK (1994) & Abu-Arefeh [79] & $1-\mathrm{y}$ & Q & 2,165 & $5-15$ & 9.7 & 11.5 & 10.6 \\
\hline \multicolumn{9}{|l|}{ Elderly } \\
\hline Italy (2001) & Prencipe [16] & $1-\mathrm{y}$ & P.i. & 833 & $\geq 65$ & 7.4 & 13.8 & 11 \\
\hline Italy (2003) & Camarda [80] & $1-y$ & P.i. & 1,031 & $\geq 65$ & 2.3 & 6.4 & 4.6 \\
\hline
\end{tabular}

For abbreviations see Table 1

Table 3 Studies on the prevalence of tension-type headache

\begin{tabular}{|c|c|c|c|c|c|c|c|c|c|c|c|}
\hline \multirow[t]{2}{*}{ Country (year) } & \multirow[t]{2}{*}{ Reference } & \multirow[t]{2}{*}{ Time frame } & \multirow[t]{2}{*}{ Method } & \multirow[t]{2}{*}{$N$} & \multirow{2}{*}{$\begin{array}{l}\text { Age range } \\
\text { (years) }\end{array}$} & \multicolumn{3}{|l|}{ TTH } & \multicolumn{3}{|c|}{ Chronic TTH } \\
\hline & & & & & & $\mathrm{M}$ & $\mathrm{F}$ & Total & $\mathrm{M}$ & $\mathrm{F}$ & Total \\
\hline \multicolumn{12}{|l|}{ Adults } \\
\hline Croatia $(2001,2003)$ & Zivadinov [49] & L.t. & P.i. & 3,794 & $15-65$ & 32.3 & 37.1 & 34.8 & & & \\
\hline Denmark (1991) & Rasmussen [10] & $1-y$ & P.i. & 740 & $25-64$ & 63 & 86 & 74 & & & \\
\hline Denmark (1991) & Rasmussen [10] & L.t. & P.i. & 740 & $25-64$ & 69 & 88 & 78 & & & 3.0 \\
\hline Denmark (2005) & Lyngberg [36] & $1-y$ & P.i. & 207 & $25-36$ & 81.5 & 90.4 & 86.5 & & & 4.8 \\
\hline Denmark (2006) & Russell [44] & $1-\mathrm{y}$ & Q & 28,195 & $12-41$ & 78.9 & 92.5 & 86.0 & 0.5 & 1.3 & 0.9 \\
\hline Georgia (2009) & Katsarava [12] & $1-y$ & P.i. & 1,145 & $\geq 16$ & & & 37.3 & & & 3.8 \\
\hline Germany (1994) & Gobel [52] & L.t. & $\mathrm{Q}$ & 4,061 & $\geq 18$ & 37 & 39 & 38 & 3.0 & 3.0 & 3.0 \\
\hline Germany (2009) & Pfaffenrath [61] & $6-\mathrm{m}$ & P.i. & 7,417 & $\geq 20$ & & & 31.5 & & & 1.25 \\
\hline Germany (2009) & Radke [62] & $1-\mathrm{y}$ & T.i. & 7,341 & $\geq 18$ & 53.0 & 66.6 & 60.2 & & & \\
\hline Norway (2008) & Grande [22] & $1-\mathrm{y}$ & Q & 20,598 & $30-44$ & & & & 1.6 & 3.7 & 2.8 \\
\hline Portugal (2005) & Pereira Monteiro [53] & L.t. & $\mathrm{Q}$ & 2,008 & All ages & & & 48.7 & & & 4.1 \\
\hline Turkey (2003) & Koseoglu [89] & $1-\mathrm{y}$ & P.i. & 1,146 & $45-64$ & & 18.8 & & & & 6.3 \\
\hline \multicolumn{12}{|l|}{ Children/youth } \\
\hline Finland (2002) & Anttila [90] & N.s. & $\mathrm{Q}$ & 1,135 & 12 & & & 12.2 & & & 0 \\
\hline Germany (2007) & Fendrich [84] & $3-\mathrm{m}$ & $\mathrm{Q}$ & 3,324 & $12-15$ & 19.1 & 21.2 & 20.2 & & & 0.2 \\
\hline Norway (2004) & Zwart [19] & $1-\mathrm{y}$ & Q & 8,255 & $13-19$ & 12.5 & 23.2 & 18.0 & & & \\
\hline Serbia (2007) & Milanovic [73] & L.t. & P.i. & 1,259 & $7-12$ & 0.9 & 1.7 & 1.3 & & & \\
\hline Sweden (2004) & Laurell [33] & $1-\mathrm{y}$ & $\mathrm{Q}$ & 1,850 & $7-15$ & 7.9 & 11.8 & 9.8 & & & \\
\hline Turkey (2005) & Bugdayci [75] & N.s. & P.i. & 5,777 & $8-16$ & & & 24.7 & & & 1.5 \\
\hline Turkey (2004) & Kaynak Key [91] & N.s. & $\mathrm{Q}$ & 2,226 & $17-21$ & 14.3 & 22.7 & 20.35 & 0.8 & 2.8 & 1.9 \\
\hline Turkey (2006) & Unalp [77] & $1-y$ & $\mathrm{Q}$ & 2,384 & $14-18$ & & & 5.7 & & & \\
\hline
\end{tabular}

For abbreviations see Table 1

Questionnaires or telephone interviews were used to screen the population, and suspected cases were interviewed by a headache specialist to confirm the diagnosis. These high prevalences are also supported by recent data from a Swedish twin registry study giving a lifetime prevalence of around $0.2 \%$ [30]. In Germany, suspected cluster headache cases detected by a questionnaire and interviewed by a neurologist in a population-based study revealed a prevalence of $0.12 \%$ [31]. In Georgia, one case was found in door-to-door survey among 1,145 individuals, which corresponds to $0.09 \%$ [32].

Increase in headache

By studying headache prevalence with an interval of some years in the same community and using the same method, it may be possible to study time-trends in headache prevalence. A study from Sweden indicates a marked increase of 
both headache and migraine in schoolchildren over a period of 40 years [33], and in a Finnish community there was a significant increase among 8-year-old children in headache (and abdominal pain) over a 10 -year period [34]. In another Finnish study, three population-based studies on migraine and other headaches among 7-year-old children conducted in 1974, 1992 and 2002 with almost identical study design indicated increased incidence rates both of headaches in general (incidence in the 3 years: 58, 156, 278/1,000 person-years) and migraine (20, 59 and 133) [35]. Among young adults (25-36 years) in Denmark, there was over a 12-year period a significant increase in TTH, particularly the frequent type. There was also a significant increase in the proportion with relatively frequent migraine, but the increase for migraine in general was not significant [36].

\section{Methodological analyses}

To explore to which degree the method of data collection in epidemiologic studies is important for the results, we compared the mean prevalence of studies in adults using either personal interview or questionnaire. For 1-year prevalences (both sexes) of migraine, the mean of the five studies using personal interview [10, 36-39] was $15.3 \%$, compared to $14.0 \%$ in the five studies using questionnaires [15, 40-44]. For headache in general, the total prevalence seemed to be higher in the three studies using personal interview [12, 37, 45] than in the eight studies using questionnaires [15, 18, 20, 42, 43, 46-48] (57.6 vs. 40.6\%). For lifetime prevalences of headache in general, the mean prevalence was somewhat higher in the four studies using personal interview $[10,45,49,50]$ than in the four using questionnaires [51-54] (84.7 vs. 71.9\%). However, for lifetime prevalences of migraine, the mean of the five studies using personal interview [10, 38, 50, 55, 56] was somewhat lower than in the four studies using questionnaires [41, 51-53] (15.9 vs. 17.9\%).

As to the effect of using different timeframes in the studies, there was little difference between the migraine prevalence in those studies in which the timeframe was not stated $[9,51]$ compared to the studies asking about headache during the last year [10, 15, 36, 37, 40-42, 49, 57] (12.9 vs. $13.0 \%)$.

\section{Discussion}

Aggregating studies that have used different methods of data collection and somewhat variable timeframes for headache (during the last year or less), the present survey indicates that more than $50 \%$ of the population in Europe are current headache sufferers, and almost $15 \%$ suffer from migraine. During the last years, more attention has been drawn to the importance of TTH on the public health, and it seems that $>60 \%$ suffer from this headache type. It is a paradox that the prevalence of TTH is higher than that of headache in general. Probably, this has to do with the way studies were performed. More detailed questions in studies aimed at making specific diagnoses may elicit higher positive rates than studies using only general questions about headache. Chronic headache (i.e. on more than 15 days per month) seems to affect around $4 \%$ of the adult population, and $\mathrm{MOH} 1-2 \%$. For cluster headache, the 1year prevalence is not known, but the lifetime prevalence seems to be around $0.2-0.3 \%$. Other primary headaches are even rarer, and the prevalence of these has not been estimated in population-based studies. The prevalence of headache and migraine is higher among women than among men [1]. In children and youth, the migraine prevalence is lower than among adults, but the prevalence of headache in general seems to be as high. Several studies also indicate a marked increase in headache prevalence over the decades, particularly in studies on children and youth, and also in one study on adults.

In this report, we have only considered the main primary headaches. One reason for this is that reasonably certain diagnosis of secondary headache requires extensive clinical and medical investigations, and often follow-up, which is not feasible in most population-based epidemiologic studies. An exception to this is medication overuse headache $(\mathrm{MOH})$ since relatively many studies attempt to estimate the prevalence of those that might have this condition ("possible $\mathrm{MOH}$ "), although a certain diagnosis of this requires both treatment and follow-up. Secondary headaches due to serious diseases with a grave prognosis are quite rare although secondary headaches related to more trivial causes, like fever or hangover, occur relatively often [58].

Most of the studies on headache prevalence so far stems from Western Europe. There are only a few studies from Eastern Europe (Georgia, Croatia, Serbia and Hungary). In addition, there are still relatively few studies on TTH. Most studies this far concern headache in general and migraine.

As to the methodological issues, we have tried to compare the results from the studies using different methods of data collection. Only for migraine and headache in general in adults could meaningful comparisons be made; in TTH or in children or elderly, there were too few studies available. In general, the figures obtained with personal interview were somewhat higher than those obtained with questionnaire. For migraine, the difference between the two methods was around $10 \%$ (15.4 vs $14.0 \%$ ) for 1-year prevalence, but almost $30 \%$ for lifetime prevalence $(22.2$ vs. $15.9 \%)$. For headache in general, the difference in 1-year prevalence was $30 \%$ (57.6 vs $40.6 \%$ ), but 
for this category, there were only three studies using personal interview, which will make the estimates less accurate. For lifetime prevalences, the figure based on questionnaire studies was $15 \%$ lower ( 84.7 vs. $71.9 \%$ ). These differences may also reflect variations in the how the ICHD-2 criteria are applied as most questionnaire studies use somewhat modified criteria, whereas studies based on personal interviews tend to use strict criteria. In sum, personal interview seem to be a somewhat more sensitive method for obtaining data on headache suffering, and questionnaires are likely to underestimate prevalences to some degree.

It has previously been demonstrated that the way the introductory screening question is asked makes a great difference in headache prevalence. Quite predictably, a neutral screening question (e.g. "have you had headache/ migraine...") will give markedly higher estimates than questions specifying some degree/severity/frequency of headache suffering (e.g. "have you suffered from headache/migraine", "have you had severe headache...?", "have you had repeated episodes of headache...?", etc.) [1]. In order to obtain answers from as many headache sufferers as possible in epidemiologic studies, it is therefore probably better to use a neutral screening question, and then ask additional questions on headache severity, frequency, duration and impact to define groups of headache sufferers that are of clinical and economical importance [1].

The ways the ICHD criteria are applied and which diagnoses are included are also of great importance. It has been found that the prevalence of migraine almost doubles if the diagnosis probable migraine (i.e. patients fulfilling all migraine criteria except one) is included $[9,20,51,59]$. Among the European studies, the highest migraine prevalences has been found in a yet unpublished study from Luxembourg (29\%) performed by one of the authors (CA). This study has used the "ID migraine" [60] which is a screening instrument consisting of only three questions. This instrument has been validated against the ICHD-2 criteria in clinical settings, showing a high sensitivity and somewhat lower specificity. Probably, this method will include many patients with probable migraine, and thereby it will tend to show higher prevalence compared to the studies using strict ICHD criteria for definite migraine.

The problem of multiple headache types occurring in the same patient may create large problems in headache epidemiologic studies. Generally, it is considered that with personal interview and examination, many different headaches can be diagnosed. With interview performed by trained personnel, migraine and TTH can be differentiated in the same person, but with questionnaires, it is usually wise to let the patient answer the questionnaire based on the altogether most bothersome headache [4].

\section{Conclusions}

The present study indicates that $50 \%$ of Europeans have an active headache disorder. However, there are large variations, and part of this variation is caused by methodological differences between studies. Around $15 \%$ seem to suffer from migraine, $4 \%$ have chronic headache and possibly $1-$ $2 \%$ medication overuse headache. During their lifetime, $0.2-0.3 \%$ has had cluster headache. Headaches are prevalent in both sexes and in all age groups, but women between 20 and 50 years are those who have the highest prevalences. Data on TTH is still too scarce in Europe, and data on prevalence of any headache is lacking from most of Eastern Europe.

As to the method to be used in headache epidemiologic studies, personal interview will give the most reliable diagnoses and the highest prevalence estimates, but when the aim was to diagnose only the most bothersome of the headaches occurring in one person, questionnaires seem to perform quite well. A neutral screening question supplemented with questions on headache severity and frequency will probably be the most sensitive method.

Open Access This article is distributed under the terms of the Creative Commons Attribution Noncommercial License which permits any noncommercial use, distribution, and reproduction in any medium, provided the original author(s) and source are credited.

\section{References}

1. Stovner LJ, Zwart JA, Hagen K, Terwindt G, Pascual J (2006) Epidemiology of headache in Europe. Eur J Neurol 13(4):333345

2. Stovner LJ, Hagen K (2006) Prevalence, burden, and cost of headache disorders. Curr Opin Neurol 19(3):281-285

3. Stovner L, Hagen K, Jensen R, Katsarava Z, Lipton R, Scher A et al (2007) The global burden of headache: a documentation of headache prevalence and disability worldwide. Cephalalgia 27(3): 193-210

4. Stovner LJ, Scher AI (2005) Epidemiology of Headache. In: Olesen J, Goadsby PJ, Ramadan NM, Tfelt-Hansen P, Welch KMA (eds) The Headaches, 3rd edn. Lippincott Williams \& Wilkins, Philadelphia, pp 17-25

5. Stovner LJ (2006) Headache epidemiology: how and why? J Headache Pain 7(3):141-144

6. Headache Classification Committee of the International Headache Society (1988) Classification and diagnostic criteria for headache disorders, cranial neuralgias and facial pain. Cephalalgia 8(Suppl 7):1-96

7. Headache Classification Subcommittee of the International Headache Society (2004) The international classification of headache disorders, 2nd edn. Cephalalgia 24(Suppl 1):1-150

8. International Headache Society (1997) ICD-10 guide for headaches. Cephalalgia 17(Suppl 19):1-91

9. Lanteri-Minet M, Valade D, Geraud G, Chautard MH, Lucas C (2005) Migraine and probable migraine-results of FRAMIG 3, a French nationwide survey carried out according to the 2004 IHS classification. Cephalalgia 25(12):1146-1158 
10. Rasmussen BK, Jensen R, Schroll M, Olesen J (1991) Epidemiology of headache in a general population-a prevalence study. $\mathrm{J}$ Clin Epidemiol 44(11):1147-1157

11. Grande RBA, Gulbrandsen K, Lundqvist P, Russell C et al (2007) Prevalence of chronic primary headache in the general population. Cephalalgia 27(6):649

12. Katsarava Z, Dzagnidze A, Kukava M, Mirvelashvili E, Djibuti M, Janelidze M et al (2009) Primary headache disorders in the Republic of Georgia: prevalence and risk factors. Neurology 73(21):1796-1803

13. Wiendels NJ, Knuistingh Neven A, Rosendaal FR, Spinhoven P, Zitman FG, Assendelft WJ et al (2006) Chronic frequent headache in the general population: prevalence and associated factors. Cephalalgia 26(12):1434-1442

14. Castillo J, Munoz P, Guitera V, Pascual J (1993) Epidemiology of chronic daily headache in the general population. Headache 39:190-196

15. Hagen K, Zwart JA, Vatten L, Stovner LJ, Bovim G (2000) Prevalence of migraine and non-migrainous headache-head-HUNT, a large population-based study. Cephalalgia 20(10):900-906

16. Prencipe M, Casini AR, Ferretti C, Santini M, Pezzella F, Scaldaferri $\mathrm{N}$ et al (2001) Prevalence of headache in an elderly population: attack frequency, disability, and use of medication. $\mathbf{J}$ Neurol Neurosurg Psychiatry 70(3):377-381

17. Lanteri-Minet M, Auray JP, El Hasnaoui A, Dartigues JF, Duru G, Henry P et al (2003) Prevalence and description of chronic daily headache in the general population in France. Pain 102(12): 143-149

18. Mitsikostas DD, Tsaklakidou D, Athanasiadis N, Thomas A (1996) The prevalence of headache in Greece: correlations to latitude and climatological factors. Headache 36(3):168-173

19. Zwart JA, Dyb G, Holmen TL, Stovner LJ, Sand T (2004) The prevalence of migraine and tension-type headaches among adolescents in Norway The Nord-Trondelag Health Study (HeadHUNT-Youth), a large population-based epidemiological study. Cephalalgia 24(5):373-379

20. Henry P, Auray JP, Gaudin AF, Dartigues JF, Duru G, LanteriMinet $M$ et al (2002) Prevalence and clinical characteristics of migraine in France. Neurology 59(2):232-237

21. Wiendels NJ, van Haestregt A, Knuistingh Neven A, Spinhoven P, Zitman FG, Assendelft WJ et al (2006) Chronic frequent headache in the general population: comorbidity and quality of life. Cephalalgia 26(12):1443-1450

22. Grande RB, Aaseth K, Gulbrandsen P, Lundqvist C, Russell MB (2008) Prevalence of primary chronic headache in a populationbased sample of 30- to 44-year-old persons. The Akershus study of chronic headache. Neuroepidemiology 30(2):76-83

23. Colas R, Munoz P, Temprano R, Gomez C, Pascual J (2004) Chronic daily headache with analgesic overuse: epidemiology and impact on quality of life. Neurology 62(8):1338-1342

24. Zwart JA, Dyb G, Hagen K, Svebak S, Holmen J (2003) Analgesic use: a predictor of chronic pain and medication overuse headache: the Head-HUNT Study. Neurology 61(2):160-164

25. Dyb G, Holmen TL, Zwart JA (2006) Analgesic overuse among adolescents with headache: the Head-HUNT-Youth Study. Neurology 66(2):198-201

26. Aaseth K, Grande RB, Kvaerner KJ, Gulbrandsen P, Lundqvist C, Russell MB (2008) Prevalence of secondary chronic headaches in a population-based sample of 30-44-year-old persons The Akershus study of chronic headache. Cephalalgia 28(7):705-713

27. Katsarava Z, Diener HC (2008) Medication overuse headache in Germany. Cephalalgia 28(11):1221-1222

28. Sjaastad O, Bakketeig LS (2003) Cluster headache prevalence Vaga study of headache epidemiology. Cephalalgia 23(7):528-533

29. Torelli P, Beghi E, Manzoni GC (2005) Cluster headache prevalence in the Italian general population. Neurology 64(3):469-474
30. Ekbom K, Svensson DA, Pedersen NL, Waldenlind E (2006) Lifetime prevalence and concordance risk of cluster headache in the Swedish twin population. Neurology 67(5):798-803

31. Katsarava Z, Obermann M, Yoon MS, Dommes P, Kuznetsova J, Weimar C et al (2007) Prevalence of cluster headache in a population-based sample in Germany. Cephalalgia 27(9):10141019

32. Katsarava Z, Dzagnidze A, Kukava M, Mirvelashvili E, Djibuti M, Janelidze M et al (2009) Prevalence of cluster headache in the Republic of Georgia: results of a population-based study and methodological considerations. Cephalalgia 29(9):949-952

33. Laurell K, Larsson B, Eeg-Olofsson O (2004) Prevalence of headache in Swedish schoolchildren, with a focus on tension-type headache. Cephalalgia 24(5):380-388

34. Santalahti P, Aromaa M, Sourander A, Helenius H, Piha J (2005) Have there been changes in children's psychosomatic symptoms? A 10-year comparison from Finland. Pediatrics 115(4):e434e442

35. Anttila P, Metsahonkala L, Sillanpaa M (2006) Long-term trends in the incidence of headache in Finnish schoolchildren. Pediatrics 117(6):e1197-e1201

36. Lyngberg AC, Rasmussen BK, Jorgensen T, Jensen R (2005) Has the prevalence of migraine and tension-type headache changed over a 12-year period? A Danish population survey. Eur J Epidemiol 20(3):243-249

37. Lampl C, Buzath A, Baumhackl U, Klingler D (2003) One-year prevalence of migraine in Austria: a nation-wide survey. Cephalalgia 23(4):280-286

38. Zivadinov R, Willheim K, Jurjevic A, Sepic-Grahovac D, Bucuk M, Zorzon M (2001) Prevalence of migraine in Croatia: a population-based survey. Headache 41(8):805-812

39. Merikangas KR, Whitaker AE, Isler H, Angst J (1994) The Zurich Study: XXIII Epidemiology of headache syndromes in the Zurich cohort study of young adults. Eur Arch Psychiatry Clin Neurosci 244(3):145-152

40. Bank J, Marton S (2000) Hungarian migraine epidemiology. Headache 40:164-169

41. Launer LJ, Terwindt GM, Ferrari MD (1999) The prevalence and characteristics of migraine in a population-based cohort: the GEM study. Neurology 53(3):537-542

42. Dahlof C, Linde M (2001) One-year prevalence of migraine in Sweden: a population-based study in adults. Cephalalgia 21(6):664-671

43. Russell MB, Kristiansen HA, Saltyte-Benth J, Kvaerner KJ (2008) A cross-sectional population-based survey of migraine and headache in 21,177 Norwegians: the Akershus sleep apnea project. J Headache Pain 9(6):339-347

44. Russell MB, Levi N, Saltyte-Benth J, Fenger K (2006) Tensiontype headache in adolescents and adults: a population based study of 33,764 twins. Eur J Epidemiol 21(2):153-160

45. Nikiforow R (1981) Headache in a random sample of 200 persons: a clinical study of a population in northern Finland. Cephalalgia 1(2):99-107

46. Michel P, Pariente P, Duru G, Dreyfus JP, Chabriat H, Henry P et al (1996) MIG ACCESS: a population-based, nationwide, comparative survey of access to care in migraine in France. Cephalalgia 16(1):50-55

47. D'Alessandro R, Benassi G, Lenzi PL, Gamberini G, Sacquegna T, De Carolis P et al (1988) Epidemiology of headache in the Republic of San Marino. J Neurol Neurosurg Psychiatry 51(1):21-27

48. Boardman HF, Thomas E, Millson DS, Croft PR (2005) One-year follow-up of headache in an adult general population. Headache 45(4):337-345

49. Zivadinov R, Willheim K, Sepic-Grahovac D, Jurjevic A, Bucuk M, Brnabic-Razmilic O et al (2003) Migraine and tension-type 
headache in Croatia: a population-based survey of precipitating factors. Cephalalgia 23(5):336-343

50. Laínez MJA, Vioque J, Hernández-Aguado I, Titus F (1994) Prevalence of migraine in Spain. An assessment of the questionnaire's validity by clinical interview. Frontiers in headache research: headache classification and epidemiology. Raven Press, Ltd., New York, pp 221-225

51. Henry P, Michel P, Brochet B, Dartigues JF, Tison S, Salamon R (1992) A nationwide survey of migraine in France: prevalence and clinical features in adults. Cephalalgia 12(4):229-237

52. Gobel H, Petersen-Braun M, Soyka D (1994) The epidemiology of headache in Germany: a nationwide survey of a representative sample on the basis of the headache classification of the International Headache Society. Cephalalgia 14(2):97-106

53. Monteiro JMP (1995) Cefaleias: Estudo Epidemiologico e clinico da uma populacao urbana, thesis

54. Boardman HF, Thomas E, Croft PR, Millson DS (2003) Epidemiology of headache in an English district. Cephalalgia 23(2):129-137

55. Celik Y, Ekuklu G, Tokuc B, Utku U (2005) Migraine prevalence and some related factors in Turkey. Headache 45(1):32-36

56. Kececi H, Dener S (2002) Epidemiological and clinical characteristics of migraine in Sivas, Turkey. Headache 42(4):275280

57. Steiner TJ, Scher AI, Stewart WF, Kolodner K, Liberman J, Lipton RB (2003) The prevalence and disability burden of adult migraine in England and their relationships to age, gender and ethnicity. Cephalalgia 23(7):519-527

58. Rasmussen BK, Olesen J (1992) Symptomatic and nonsymptomatic headaches in a general population. Neurology 42(6): 1225-1231

59. Gobel H (1994) Paper-pencil tests for retrospective and prospective evaluation of primary headaches on the basis of the IHS criteria. Headache 34(10):564-568

60. Lipton RB, Dodick D, Sadovsky R, Kolodner K, Endicott J, Hettiarachchi $J$ et al (2003) A self-administered screener for migraine in primary care: the ID Migraine validation study. Neurology 61(3):375-382

61. Pfaffenrath V, Fendrich K, Vennemann M, Meisinger C, Ladwig $\mathrm{KH}$, Evers S et al (2009) Regional variations in the prevalence of migraine and tension-type headache applying the new IHS criteria: the German DMKG Headache Study. Cephalalgia 29(1):48-57

62. Radtke A, Lempert T, Gresty MA, Brookes GB, Bronstein AM, Neuhauser H (2002) Migraine and Meniere's disease: is there a link? Neurology 59(11):1700-1704

63. Molarius A, Tegelberg A (2006) Recurrent headache and migraine as a public health problem - a population-based study in Sweden. Headache 46(1):73-81

64. Boru UT, Kocer A, Luleci A, Sur H, Tutkan H, Atli H (2005) Prevalence and characteristics of migraine in women of reproductive age in Istanbul, Turkey: a population based survey. Tohoku J Exp Med 206(1):51-59

65. Waters WE, O'Connor PJ (1975) Prevalence of migraine. J Neurol Neurosurg Psychiatry 38(6):613-616

66. Crisp AH, Kalucy RS, McGuinness B, Ralph PC, Harris G (1977) Some clinical, social and psychological characteristics of migraine subjects in the general population. Postgrad Med J 53(625):691-697

67. Boardman HF, Thomas E, Millson DS, MacGregor EA, Laughey WF, Croft PR (2003) North Staffordshire Headache Survey: development, reliability and validity of a questionnaire for use in a general population survey. Cephalalgia 23(5):325-331

68. Sillanpää M (1983) Prevalence of headache in prepuberty. Headache 23(1):10-14
69. Metsähonkala L, Sillanpää M (1994) Migraine in children-an evaluation of the IHS criteria. Cephalalgia 14(4):285-290

70. Sillanpaa M, Piekkala P, Kero P (1991) Prevalence of headache at preschool age in an unselected child population. Cephalalgia 11(5):239-242

71. Roth-Isigkeit A, Thyen U, Raspe HH, Stöven H, Schmucker P (2004) Reports of pain among German children and adolescents: an epidemiological study. Acta Paediatr 93(2):258-263

72. Raieli V, Raimondo D, Cammalleri R, Camarda R (1995) Migraine headaches in adolescents: a student population-based study in Monreale. Cephalalgia 15(1):5-12

73. Milovanovic M, Jarebinski M, Martinovic Z (2007) Prevalence of primary headaches in children from Belgrade, Serbia. Eur J Paediatr Neurol 11(3):136-141

74. Bille B (1962) Migraine in school children. A study of the incidence and short-term prognosis, and a clinical, psychological and electroencephalographic comparison between children with migraine and matched controls. Acta Paediatr 51:1-151

75. Bugdayci R, Ozge A, Sasmaz T, Kurt AO, Kaleagasi H, Karakelle A et al (2005) Prevalence and factors affecting headache in Turkish schoolchildren. Pediatr Int 47(3):316-322

76. Karli N, Akis N, Zarifoglu M, Akgoz S, Irgil E, Ayvacioglu U et al (2006) Headache prevalence in adolescents aged 12 to 17: a student-based epidemiological study in Bursa. Headache 46(4):649-655

77. Unalp A, Dirik E, Kurul S (2006) Prevalence and characteristics of recurrent headaches in Turkish adolescents. Pediatr Neurol 34(2):110-115

78. Deubner DC (1977) An epidemiologic study of migraine and headache in 10-20 year olds. Headache 17(4):173-180

79. Abu-Arefeh I, Russell G (1994) Prevalence of headache and migraine in schoolchildren. BMJ 309(6957):765-769

80. Camarda R, Monastero R (2003) Prevalence of primary headaches in Italian elderly: preliminary data from the Zabut Aging Project. Neurol Sci 24(Suppl 2):S122-S124

81. Russell MB, Rasmussen BK, Thorvaldsen P, Olesen J (1995) Prevalence and sex-ratio of the subtypes of migraine. Int J Epidemiol 15(1):612-618

82. Sjaastad O, Bakketeig LS (2008) Migraine without aura: comparison with cervicogenic headache. Vaga study of headache epidemiology. Acta neurol Scand 117(6):377-383

83. Mattsson P, Svardsudd K, Lundberg PO, Westerberg CE (2000) The prevalence of migraine in women aged 40-74 years: a population-based study. Cephalalgia 20(10):893-899

84. Fendrich K, Vennemann M, Pfaffenrath V, Evers S, May A, Berger $\mathrm{K}$ et al (2007) Headache prevalence among adolescentsthe German DMKG headache study. Cephalalgia 27(4):347-354

85. Heinrich M, Morris L, Kroner-Herwig B (2009) Self-report of headache in children and adolescents in Germany: possibilities and confines of questionnaire data for headache classification. Cephalalgia 29(8):864-872

86. Mavromichalis I, Anagnostopoulos D, Metaxas N, Papanastassiou E (1999) Prevalence of migraine in schoolchildren and some clinical comparisons between migraine with and without aura. Headache 39(10):728-736

87. Zencir M, Ergin H, Sahiner T, Kilic I, Alkis E, Ozdel L et al (2004) Epidemiology and symptomatology of migraine among school children: Denizli urban area in Turkey. Headache 44(8):780-785

88. Akyol A, Kiylioglu N, Aydin I, Erturk A, Kaya E, Telli E et al (2007) Epidemiology and clinical characteristics of migraine among school children in the Menderes region. Cephalalgia 27(7):781-787

89. Koseoglu E, Nacar M, Talaslioglu A, Cetinkaya F (2003) Epidemiological and clinical characteristics of migraine and tension 
type headache in 1146 females in Kayseri, Turkey. Cephalalgia 23(5):381-388

90. Anttila P, Metsahonkala L, Aromaa M, Sourander A, Salminen J, Helenius $\mathrm{H}$ et al (2002) Determinants of tension-type headache in children. Cephalalgia 22(5):401-408
91. Kaynak Key FN, Donmez S, Tuzun U (2004) Epidemiological and clinical characteristics with psychosocial aspects of tensiontype headache in Turkish college students. Cephalalgia 24(8): 669-674 